\title{
Transcription Factor Families Regulate the Anthocyanin Biosynthetic Pathway in Capsicum annuum
}

\author{
John R. Stommel ${ }^{1}$ \\ United States Department of Agriculture, Agricultural Research Service, Beltsville Agricultural \\ Research Center, Genetic Improvement of Fruits and Vegetables Laboratory, Plant Sciences Institute, \\ Beltsville, MD 20705

\begin{abstract}
Gordon J. Lightbourn and Brenda S. Winkel VA 24061

Robert J. Griesbach

United States Department of Agriculture, Agricultural Research Service, Beltsville Agricultural

Research Center, Floral and Nursery Plant Research Unit, United States National Arboretum,

Beltsville, MD 20705
\end{abstract} \\ Biological Sciences Department, Virginia Polytechnic Institute and State University, Blacksburg,
}

\begin{abstract}
Additional IndeX words. Ans, Chs, delphinidin, $D f r, M y b, M y c$, pepper, WD40
Abstract. Anthocyanin structural gene transcription requires the expression of at least one member of each of three transcription factor families: MYC, MYB, and WD40. These transcription factors form a complex that binds to structural gene promoters, thereby modulating gene expression. Capsicum annuum L. (pepper) displays a wide spectrum of tissue-specific anthocyanin pigmentation, making it a useful model for the study of anthocyanin accumulation. To determine the genetic basis for tissue-specific pigmentation, we used real-time polymerase chain reaction to evaluate the expression of anthocyanin biosynthetic ( $C h s, D f r$, and $A n s)$ and regulatory $\left(M y c, M y b_{A}\right.$, and $W d$ ) genes in flower, fruit, and foliar tissue from pigmented and nonpigmented $C$. annuum genotypes. No differences were observed in expression of the $W d$ gene among these tissues. However, in all cases, biosynthetic gene transcript levels were significantly higher in anthocyanin-pigmented tissue than in nonpigmented tissues. $M y b_{A}$ and $M y c$ transcript levels were also substantially higher in anthocyanin-pigmented floral and fruit tissues. Our results demonstrate that differential expression of $C$. annuum $M y b_{A}$ as well as $M y c$ occurs coincident with anthocyanin accumulation in $C$. annuum flower and fruit tissues. In contrast to the situation in flowers and fruit, differential expression of $M y b_{A}$ and $M y c$ was not observed in foliar tissue, suggesting that different mechanisms contribute to the regulation of anthocyanin biosynthesis in different parts of the $C$. annuum plant. Cloning and sequencing of $M y b_{A}$ genomic and cDNA clones revealed two introns of 249 and 441 bp between the R2R3 domains. Whereas the Myb R2R3 domains were conserved between $C$. annuum and Petunia $\times$ hybrida Vilm., the sequence of the non-R2R3 domains was not conserved, with very little homology in these related Solanaceous species.
\end{abstract}

Pigmentation of plant vegetative tissue, including leaves, stems, and roots and reproductive tissue in flowers and fruit, is attributed to anthocyanin and carotenoid pigments. These colored compounds are produced by independent metabolic pathways and are responsible for yellow to orange coloration and gradations of red through blue. Anthocyanins arise from the phenylpropanoid pathway and are heterocyclic compounds consisting of a three-ring skeleton with sugar and acyl moieties attached at specific locations. Anthocyanin pigments serve a wide variety of functions in plants that include protection against ultraviolet and oxidative light stress, feeding deterrents, insect pollinator attraction, and seed dispersal. Anthocyanins play a role in consumer preference for flower and fruit quality,

Received for publication 1 Oct. 2008. Accepted for publication 14 Jan. 2009. This work was supported by a Cooperative Research and Development Agreement (58-3K95-5-1074) with McCorkle Nursery and Kerry's Bromeliad Nursery.

The mention of trade names or commercial products is solely for the purpose of providing specific information and does not imply recommendation or endorsement by the United States Department of Agriculture.

${ }^{1}$ Corresponding author. E-mail: john.stommel@ars.usda.gov. potential food health properties, and related horticultural attributes. As a result, classical breeding, as well as transgene technologies, have been used to enhance or create novel colors in ornamental and food crops.

The biochemistry and genetics of anthocyanin-based pigmentation has been studied extensively since early work by Mendel in the 1800s on pea (Pisum sativum L.) flower color. Model systems for study of anthocyanin accumulation include Zea mays L., Petunia $\times$ hybrida, Antirrhinum majus L., and Arabidopsis thaliana (L.) Heynh. (Griesbach, 2005; Holton and Cornish, 1995; Winkel-Shirley, 2001). The enzymes in the anthocyanin biosynthetic pathway are well characterized and many of the genes encoding these enzymes have been cloned and share high sequence similarity across species and typically exhibit tissue- or development-specific expression.

Six enzymes are generally involved in anthocyanin biosynthesis. Chalcone synthase (CHS) is the first enzymatic step of the biosynthetic pathway. Twelve different CHS genes (ChsA, B, C, D, E, F, G, H, I, J, K, and $L$ ) have been identified in $P$. Xhybrida (Koes et al., 1989) and two (c2 and whp) in $Z$. mays (Coe et al., 1981; Dooner, 1983). Chalcone is isomerized 
by chalcone isomerase $(\mathrm{CHI})$ to naringenin. Two $\mathrm{CHI}$ genes (chiA and $c h i B$ ) have been identified in $P$. $\times$ hybrida (van Tunen et al., 1988, 1989) and three CHI homologues are present in some Z. mays genotypes (Grotewold and Peterson, 1994). Flavanone 3-hydroxylase $(\mathrm{F} 3 \mathrm{H})$ converts naringen into dihydrokaempferol. The dihydroflavonols are subsequently converted to anthocyanins by the action of three enzymes. Dihydroflavonol is first converted to a colorless leucoanthocyanidin by dihydroflavonol 4-reductase (DFR). Three different DFR genes ( $d$ fr $A, d f r B$, and $d f r C$ ) have been described in $P . \times$ hybrida (Huits et al., 1994). The $d f r A$ gene corresponds to the $P$. $\times$ hybrida An6 locus. Leucoanthocyanidins are subsequently converted to colored anthocyanidins by anthocyanidin synthase (ANS). Finally, UDP-glucose-flavonoid 3-O-glucosyltransferase (UFGT) creates the anthocyanin-3-glucoside. Two UFGT gene copies have been identified in P. $\times$ hybrida (Yamazaki et al., 2002). CHS is the first and key regulatory enzyme of flavonoid biosynthesis, and DFR is the first committed enzyme of anthocyanin biosynthesis in the flavonoid pathway (Griesbach, 2005).

Tissue- or developmental-specific expression exhibited by anthocyanin structural genes is controlled by regulatory genes. A common set of proteins, comprised of MYB and bHLH MYC proteins plus WD40 repeat proteins, interact to form a regulatory complex that controls transcription of anthocyanin structural genes (Ramsay and Glover, 2005). Most plant MYB proteins are characterized by two (R2 and R3) imperfect repeats of the conserved MYB DNA-binding motif (Martin and PazAres, 1997). Each repeat encodes three $\alpha$-helices, with the second and third helices forming a helix-turn-helix (HTH) structure when bound to DNA. Anthocyanin-related R2R3MYB proteins were first characterized in $Z$. mays where anthocyanin accumulation requires the R2R3-MYB proteins $\mathrm{C} 1$ for seed pigmentation and $\mathrm{Pl}$ for pigmentation in other plant tissues (Cone et al., 1986, 1993). The MYC class of proteins is defined by a conserved basic helix-loop-helix domain consisting of a presumed DNA-binding basic region and a proteinprotein dimerization motif. Plant MYC proteins were also first identified in Z. mays, where R-like MYC proteins determine the timing, amount, and distribution of anthocyanin pigmentation. The $R$ gene family consists of the $R$ locus, which also includes $S, L c$, and $S n$, and the $B$ locus (Dooner et al., 1991). R-like MYC proteins were shown to physically interact with $\mathrm{C} 1 \mathrm{MYB}$ proteins to coactivate anthocyanin synthesis by directly binding to the promoters of the biosynthetic genes.

The third component of the anthocyanin regulatory protein complex is represented by a family of WD40 repeat (WDR) proteins (deVetten et al., 1997; Smith, 1999). They comprise a 40-residue WD motif core region that contains the glycinehistidine $(\mathrm{GH})$ dipeptide at the N-terminus and the tryptophanaspartate (WD) dipeptide at the C-terminus. The WD motif is tandemly repeated four to 16 times and forms the WDR protein, a conserved $\beta$-propeller structure that acts as a stable surface to facilitate protein-protein interactions. Plant anthocyaninrelated WD40 proteins include the $Z$. mays PAC1 and $P$. $\times$ hybrida AN11 proteins (Carey et al., 2004; deVetten et al., 1997). In a functional MYB-MYC-WD complex, the MYB factor is hypothesized to bind directly to the cis-element of the structural gene, while R-like MYC might bind indirectly via a hypothetical $\mathrm{R}$ interaction protein (RIP) (Ramsay and Glover, 2005). R-like MYC is centered in the complex that interacts with a MYB factor with WD proteins on its sides. Together, they activate the entire set of anthocyanin biosynthesis genes.
The anthocyanin pigment found in Capsicum annuum leaves, flowers, and immature fruit is delphinidin-3-p-coumaroylrutinoside-5-glucoside (Lightbourn et al., 2008). Anthocyanin accumulation in $C$. annuum is reportedly influenced by an incompletely dominant gene $A$ and a second modifying gene $M o A$ (Deshpande, 1933; Peterson, 1959). The $A$ locus encodes a $M y b$ transcription factor $\left(M y b_{A}\right)$ that is absent in genotypes that do not accumulate anthocyanin (Borovsky et al., 2004). Consistent with these reports, we previously demonstrated that anthocyanin accumulation in immature $C$. annuum fruit was simply inherited with modifying gene action (Stommel and Griesbach, 2008). In contrast with fruit color, inheritance of leaf color in anthocyanin accumulating foliar mutants was complex, involving the action of multiple genes (Lightbourn et al., 2007; Stommel and Griesbach, 2008). To further characterize the tissue-specific regulation of the anthocyanin biosynthetic pathway in C. annuum, we compared the expression of the anthocyanin regulatory gene complex $\left(M y b_{A}\right.$, $M y c$, and $W d$ ) and three structural genes (Chs, Dfr, and Ans) between genotypes with anthocyanin-free and anthocyanincontaining flowers, fruit, and leaves.

\section{Materials and Methods}

Plant material and growing conditions. C. annuum, plants of true-breeding U.S. Department of Agriculture (USDA) breeding lines divergent for anthocyanin accumulation in flower, fruit, and leaf tissues were produced from seed and grown under standard greenhouse conditions for $C$. annuum (Stommel and Bosland, 2006). Line 06C19-2 produced white flowers, green immature fruit, and green foliage. Line 06C59 produced purple flowers, black immature fruit, and black foliage. These inbred lines share a common pedigree but are divergent for anthocyanin pigmentation.

Flavonoid ANALYSIS. Analytical high-performance liquid chromatography (HPLC) (Griesbach et al., 1991) was used to quantify the anthocyanin pigments in black foliage and immature black $C$. annuum fruit. Anthocyanins from flower, fruit, and leaf tissue were extracted in acidified methanol $(1 \% \mathrm{HCl})$, evaporated to dryness, washed with acetone, and resolublized in acidified methanol. HPLC characterization of anthocyanidins was performed on a $7.8 \times 300-\mathrm{mm}$ column of $5-\mu \mathrm{m}$ Bondapak C18 (Waters, Milford, MA) using a 30-min linear gradient of $0 \%$ to $10 \%(\mathrm{v} / \mathrm{v})$ acetonitrile in aqueous $1.5 \%(\mathrm{v} / \mathrm{v})$ phosphoric acid and $15 \%(\mathrm{v} / \mathrm{v})$ acetic acid followed by a $10-\mathrm{min}$ linear increase to $20 \%(\mathrm{v} / \mathrm{v})$ acetonitrile and held at $20 \%(\mathrm{v} / \mathrm{v})$ acetonitrile for an additional $20 \mathrm{~min}$. The flow rate was $1.0 \mathrm{~mL} /$ min and detection was by absorption at $540 \mathrm{~nm}$. Anthocyanins were identified as previously described (Lightbourn et al., 2008). The amount of anthocyanin was determined by measuring the peak area of three replicate samples using the Maxima software (Waters). The relative amount of pigment was calculated as the mean of the area of absorption per gram of fresh weight of three replicates.

GENE EXPRESSION. Flowers, immature fruit, and leaves were harvested from actively growing plants, frozen in liquid nitrogen, and stored at $-80{ }^{\circ} \mathrm{C}$. Total RNA was isolated from $\approx 100 \mathrm{mg}$ frozen tissue using the RNeasy Plant Mini Kit with the optional DNase digest (Qiagen, Valencia, CA). RNA quantity was recorded using a spectrophotometer (ND1000; NanoDrop Technologies, Wilmington, DE) and integrity and quantification were confirmed using an Agilent 2100 Bioanalyzer (Agilent Technologies, Santa Clara, CA). 
Real-time polymerase chain reaction (PCR) was used to compare flavonoid gene expression ( $C h s, D f r, A n s, M y b_{A}, M y c$, and $W d$ ) between anthocyanin-pigmented and nonpigmented tissues collected from contrasting genotypes. C. annuum specific primers were used for $M y b_{A}$ identification (Borovsky et al., 2004). Degenerate primer sets from $P$. $\times$ hybrida (Griesbach and Beck, 2005) were used to generate PCR products from all other genes. PCR products amplified using degenerate primers were cloned and sequenced to develop PCR primers for amplification of gene-specific products from C. annuum. Primer sequences, with the exception of $M y b_{A}$ (forward 5'-AGA TTG CCG GGA AGA ACA GCA AAC-3'; reverse 5'-TTG CAC TTG ATG AGA AGG TCC GAG-3'), were previously described (Lightbourn et al., 2007). For realtime PCR, cDNA synthesis was performed with $1 \mu \mathrm{g}$ of RNA using the iScript ${ }^{T M}$ cDNA Synthesis Kit (Bio-Rad, Hercules, CA). Real-time PCR amplification of the cDNA was carried out as described by Lightbourn et al. (2007) using the iCycler $1 \mathrm{Q}^{\mathrm{TM}}$ Multicolor Real-Time Detection System (Bio-Rad). Results were normalized to the expression of tubulin $(T u b)$ where degenerate primers were designed based on gene sequences reported in GenBank (forward 5'-TGG CTA CCA TCA AGA CTA AGC GCA-3'; reverse 5'-AGA CCT CAG CAA CAC TGG TTG AGT-3'). Normalization to Tub was substantiated by comparison with normalization to expression of the $18 \mathrm{~S}$ ribosomal gene (QuantumRNA ${ }^{\mathrm{TM}}$ 18S Internal Standards; Ambion, Austin, TX).

Standard calibrations were computed and the efficiency of reaction kinetics and $\mathrm{R}$ values were tabulated and found to fall within the range of $95 \%$ to $105 \%$ (efficiency) and 0.98 to 1.0 (R value). Each genotype was represented by four replicates. Threshold values [Ct (iQ ${ }^{\mathrm{TM}} 5$ v 2.0; Bio-Rad)] were manually checked for $\mathrm{SD}>0.5$ within triplicate reactions. Normalized relative fold expression values were derived using the Pfaffl method (Pfaffl, 2001), and pairwise comparisons between means were made using T-tests.

Myв $_{\mathbf{A}}$ SEQuencing. A full-length $M y b_{A}$ genomic clone was generated by PCR using PfuUltra II Fusion HS DNA polymerase (Stratagene, La Jolla, CA) and the $M y b_{A}$ primers (forward 5'-GAT ATC ATG AAT ACT GCT ATT-3'; reverse 5'-CTT ACA TTG AAG ATG CGT GGA-3') described by Borovsky et al. (2004). PCR products of expected size, obtained after 35 cycles of $95^{\circ} \mathrm{C}$ for $20 \mathrm{~s}, 57^{\circ} \mathrm{C}$ for $20 \mathrm{~s}$, and $72{ }^{\circ} \mathrm{C}$ for $60 \mathrm{~s}$, were purified from the gel and cloned using the StrataClone Blunt PCR Cloning kit (Stratagene) and the associated TA cloning kits when post-PCR 3'-A addition by Taq DNA polymerase was performed. Plasmid DNA was purified using Genelute Plasmid Mini-Prep Kit (Sigma, St. Louis) and was commercially sequenced (Macrogen, Rockville, MD) to identify the correct clones. All the sequence data were edited manually based on the chromatogram output files before being blastx searched against the GenBank nr database.

The 5' untranslated region (UTR) region was analyzed following the GeneRacer Kit protocol (Invitrogen, Carlsbad, CA). Purple flowers were used to generate a $5^{\prime}-\mathrm{RACE}$ ready cDNA PCR template. Using forward and forward-nested primers provided in the GeneRacer kit and reverse and reverse-nested primers designed from the proximal $5^{\prime}$ region of the $M y b_{A}$ ORF, PCR products representing the 5' UTR were formed. The reverse primer was 5'-CTC CAG AGG ACT TGG CAA TAA TAG CAG-3', and the nested reverse primer was 5'-AGA GGA CTT GGC AAT AAT AGC AGT ATT C-3'.
The amplified 5' products were cloned using the StrataClone Blunt PCR Cloning kit (Stratagene). Cloned products were sequenced and forward primers designed to confirm clone identity. The primers were 5'-CAA AGA GCA AGG GAC ACA GCT-3'. Resulting PCR products were cloned and sequenced as described above.

\section{Results}

Two related genotypes of common pedigree with contrasting anthocyanin pigmentation were selected for gene expression studies. Line 06C59 produced purple-colored flowers and black fruit and foliage, while line 06C19-2 flowers were white in color, and fruit and foliage were green. Even though line 06C19-2 lacked anthocyanin in the flowers, fruit, and foliage, it did contain anthocyanin pigment in stem internodes. Therefore, functional copies of the anthocyanin genes must be present and the lack of anthocyanin in the flowers, fruit, and foliage must be the result of differential tissue-specific gene expression.

In agreement with previous analysis of independent genotypes (Lightbourn et al., 2008), HPLC analyses demonstrated that anthocyanin-pigmented tissues in line 06C59 contained a single major anthocyanin compound, delphinidin-3-pcoumaroyl-runtinoside-5-glucoside. Black pigmentation, in contrast to purple pigmentation, is attributed to high concentrations of chlorophyll in combination with anthocyanin in $C$. annuum fruit and foliar tissues (Lightbourn et al., 2008). Flower, fruit, and leaf tissues of line 06C19-2 contained little or no anthocyanin compared with line 06C59 (Table 1).

To determine the genetic basis for tissue-specific pigmentation, we evaluated the expression of anthocyanin biosynthetic (Chs, Dfr, and $A n s)$ and regulatory $\left(M y c, M y b_{A}\right.$, and $W d$ ) genes in flower, fruit, and foliar tissue from anthocyanin-pigmented (06C59) and nonpigmented (06C19-2) genotypes. In all cases, biosynthetic gene transcript levels were significantly higher in anthocyanin-pigmented tissues in comparison with nonanthocyanin-pigmented tissues. Levels of Chs, Dfr, and Ans transcript were 16-, 240-, and 56-fold higher, respectively, in anthocyanin-pigmented flowers of 06C59 in comparison with white flowers of line 06C19-2 (Fig. 1A). Similar to flowers, $C h s, D f r$, and Ans displayed the greatest fold difference in transcript levels between fruit of anthocyanin-pigmented versus green-colored fruit (20-, 95-, and 195-fold greater for Chs, Dfr, and $A n s$, respectively) (Fig. 1B). In foliar tissue, Ans exhibited the greatest fold difference in transcript level between anthocyanin-pigmented versus green-colored leaves relative to that observed for Chs and Dfr (13-, 13-, and 42-fold greater for Chs, $D f r$, and $A n s$, respectively) (Fig. 1C).

Table 1. Anthocyanin content in flowers, fruit, and leaves of Capsicum annuum genotypes 06C19-2 (nonanthocyanin pigmented: white flowers, green fruit, green foliage) and 06C59 (anthocyanin pigmented: purple flowers, black fruit, black leaves).

\begin{tabular}{lcc}
\hline & \multicolumn{2}{c}{ Genotype } \\
\cline { 2 - 3 } Tissue & \multicolumn{2}{c}{ (peak area $/ g$ fresh wt tissue $) \times 10^{3}$} \\
\cline { 2 - 3 } Flower & 0 & $42,682 \pm 4,246$ \\
Fruit & $4.7 \pm 1.1$ & $1,600 \pm 439$ \\
Leaf & $16.8 \pm 4.6$ & $27,148 \pm 5,487$ \\
\hline
\end{tabular}



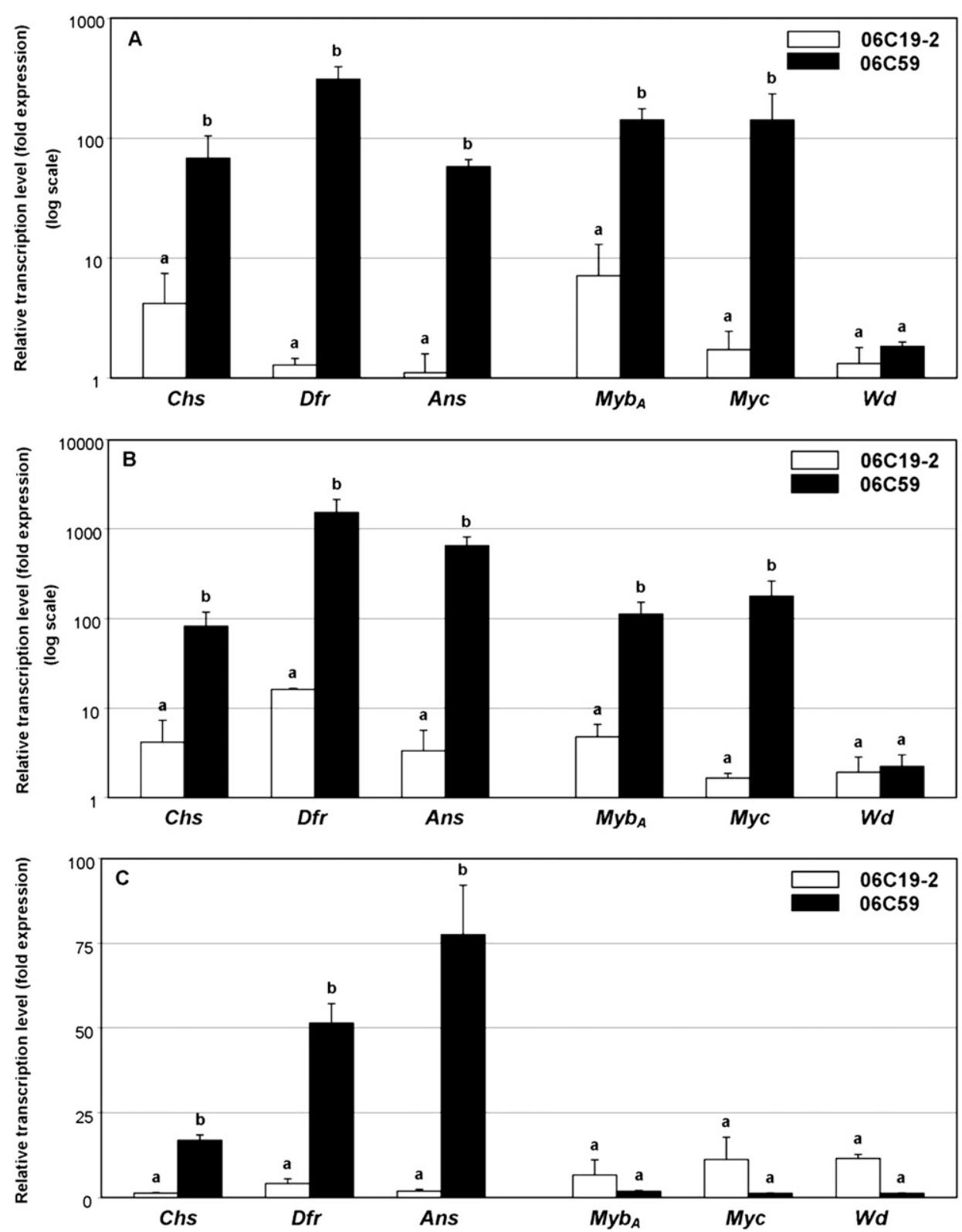

Fig. 1. Flavonoid structural (Chs, $D f r$, and $A n s)$ and regulatory $\left(M y b_{A}, M y c\right.$, and $W d$ ) gene expression in (A) flower, (B) fruit, and (C) leaf tissue of Capsicum annuиm line 06C19-2 (nonanthocyanin pigmented: white flowers, green fruit, green foliage) and line 06C59 (anthocyanin pigmented: purple flowers, black fruit, black leaves). Gene expression was measured using real-time PCR and normalized to tubulin gene expression. Data are presented as the mean of three replicates. Error bars represent SE \pm mean. Letters denote Fisher's least significant difference multiple comparison test $(P \leq 0.001)$; means followed by the same letter are not significantly different.

Consistent with elevated levels of structural gene transcript in anthocyanin-pigmented tissues, anthocyanin-specific $M y b_{A}$ and $M y c$ transcript levels were significantly higher in anthocyanin-pigmented fruit and floral tissues (Fig. 1, A and B). $M y b_{A}$ transcript levels were $\approx 20$-fold greater in anthocyanin-pigmented flowers and fruit (06C59) in comparison with white flower and green fruit tissue (06C19-2). Myc showed an $\approx 40$ fold increase in pigmented versus unpigmented flowers and fruit. In contrast to $M y b_{A}$ and $M y c, W d$ transcript levels in pigmented flowers and fruit (06C59) was very low and did not differ significantly from unpigmented tissue (06C19-2; Fig. 1, $\mathrm{A}$ and $\mathrm{B})$.
In leaf tissue, there was no significant difference in $M y b_{A}, M y c$, and $W d$ transcript levels between anthocyanin-pigmented (06C59) and unpigmented (06C19-2) lines (Fig. 1C). The $M y b_{A}$ and $M y c$ transcript levels in anthocyanin-pigmented leaf tissue of $06 \mathrm{C} 59$ were significantly lower than those found in anthocyanin-pigmented flower and fruit tissue of this genotype. About equivalent levels of $M y b_{A}$ and $M y c$ transcript were noted in nonanthocyanin-pigmented flower, fruit, and leaf tissue of 06C19-2. The $W d$ transcript level was about the same in flower, fruit, and leaf tissue.

Analysis of the full-length $M y b_{A}$ genomic clone revealed a $1652-b p$ sequence containing two introns of 249 and 441 bp (Fig. 2). 5' -RACE was used to derive an UTR sequence upstream of the coding region in $M y b_{A}$.

\section{Discussion}

C. annuum displays a wide spectrum of tissue-specific anthocyanin pigmentation, making it a useful model for the study of anthocyanin accumulation. Differential expression of $C h s, D f r$, and Ans structural genes was observed in anthocyaninpigmented versus nonanthocyaninpigmented $C$. annuиm flower, fruit, and leaf tissues. In anthocyaninpigmented tissues, all three structural genes were markedly upregulated. Borovsky et al. (2004) reported that the $C h s$ structural gene was expressed in leaves, flowers, and fruit of an anthocyanin-containing C. annuиm genotype (5226), as well as in an anthocyanin-free $C$. chinense Jacq. (PI 159234) accession. Differential expression of Chs was not observed between these two genotypes with contrasting anthocyanin pigmentation. In the anthocyanin-containing genotype (5226), they found that $D f \mathrm{r}$ and $A n s$ were upregulated in immature fruit before accumulation of visible anthocyanins. No transcript was evident in purple-pigmented fruit, flowers, or leaves of 5226. Because Dfr and Ans transcript are required for anthocyanin production, we suggest that $D f r$ and Ans transcript in anthocyanin-pigmented fruit may be more transient in 5226. Dfr and Ans were not expressed in leaves, flowers, and fruit of the anthocyanin-free PI 159234. In contrast, we demonstrated that in the anthocyanin-containing genotype (06C59) we studied, $C h s, D f r$, and $A n s$ were all upregulated in anthocyaninpigmented flower, fruit, and leaf tissues. Differential regulation 


\begin{tabular}{|c|c|c|c|c|}
\hline Myb59 gDNA & 10 & 20 & 30 & 40 \\
\hline Myb59 CDNA & & & & \\
\hline $\mathrm{Ca} \mathrm{A}$ & & & & ACGCGGGGAA \\
\hline $\mathrm{Ph}$ An2 & CTTTTAATTT & CAATAATGCA & CCTCCTTTTA & ATTTGCTTAA \\
\hline & 110 & 120 & 130 & 140 \\
\hline Myb59 gDNA & TGAATACTGC & TATTATTGCC & AAGTCCTCTG & GAGTGAGGAA \\
\hline Myb59 cDNA & TGAATACTGC & TATTATTGCC & AAGTCCTCTG & GAGTGAGGAA \\
\hline $\mathrm{Ca} \mathrm{A}$ & TGAATACTGC & TATTATTGCC & AAGTCCTCTG & GAGTGAGGAA \\
\hline $\mathrm{Ph}$ An2 & TGAGTACTTC & TAATGC-ATC & AA- - CATCAG & GAGTAAGGAA \\
\hline & & & & \\
\hline & 210 & 220 & 230 & 240 \\
\hline Myb59 gDNA & AGGAAAGTGG & СATCTTGTTC & CCATTAGAGC & TGGTAATATT \\
\hline Myb59 Cdna & AGGAAAGTGG & CATCTTGTTC & CCATTAGAGC & TGGT-... \\
\hline $\mathrm{Ca} \mathrm{A}$ & AGGAAAGTGG & CATCTTGTTC & CCATTAGAGC & TGGT-....... \\
\hline $\mathrm{Ph}$ AnN2 & AGGAAAGTGG & $\frac{\text { CATCTAGTTC }}{\mathrm{R} 2}$ & CAGTTAGAGC & TGGT -......... \\
\hline & & 320 & 330 & 340 \\
\hline Myb59 gDNA & TTCTTAGTAT & CATGTTCATT & ATATATTTAA & AATTATAGGT \\
\hline Myb59 cDNA & and & . & . & and \\
\hline $\begin{array}{l}\mathrm{Ca} \mathrm{A} \\
\mathrm{Ph} \text { An2 }\end{array}$ & (1) & - & - & - \\
\hline & 410 & 420 & 430 & 440 \\
\hline Myb59 gDNA & ACTCACGTCT & GAAGTATCGA & ATTCAAATGG & TCGGGGCGAA \\
\hline Myb59 CDNA & .......... & 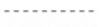 & .......... & .......... \\
\hline $\begin{array}{l}\text { a A } \\
\text { Ph An2 }\end{array}$ & - & - & - & - \\
\hline & 510 & 520 & 530 & 540 \\
\hline Myb59 gDNA & AGGGTCTTCT & AGAAACATTT & TCTTTATCAG & ATAAGGTAGG \\
\hline Myb59 cDNA & & & & -............ \\
\hline & -.......... & ............ & - & 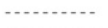 \\
\hline $\mathrm{Ph}$ An2 & - & ...ent. & 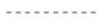 & n.ence. \\
\hline & & 620 & 630 & 640 \\
\hline Myb59 gDNA & GTTATCATTA & GATAAGAGTA & TATGCATATA & GCATCTGATA \\
\hline Myb59 CDNA & & & & \\
\hline & nenen. & . & 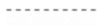 & - \\
\hline Ph An2 & - & ......... & .......... & .......... \\
\hline & & & & \\
\hline & 710 & 720 & 730 & 740 \\
\hline Myb59 gDNA & GATTGAGGTG & GCTGAATTAT & CTAAGGCCGC & ATATAAAGAG \\
\hline Myb59 cDNA & GATTGAGGTG & GCTGAATTAT & CTAAGGCCGC & ATATAAAGAG \\
\hline $\mathrm{Ca} A$ & GATTGAGGTG & GCTGAATTAT & CTAAGGCCGC & ATATAAAGAG \\
\hline $\mathrm{Ph}$ An2 & GACTTAGGTG & GTTGAATTAT & CTAAGGCCAC & ATATAAAAAG \\
\hline & & R2 & & .• \\
\hline & & 820 & 830 & 840 \\
\hline Myb59 gDNA & CAGGCAAGTT & CATGTTCAAA & САCTTTGATT & GATGGCCATA \\
\hline Myb59 cDNA & CAG-........ & & & ........ \\
\hline 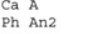 & $\begin{array}{l}\text { CAG- } \\
\text { CAG- }\end{array}$ & a & n. & "1, \\
\hline & & 920 & & \\
\hline Myb59 gDNA & ACTTCGCAAA & ATGCTTTTTC & САACTTCTTA & TCTTAACTAA \\
\hline Myb59 cDNA & & & & \\
\hline Ca A & ............ & ............ & . & . \\
\hline Ph An2 & . & . & . & .......... \\
\hline & 1010 & 1020 & 1030 & 1040 \\
\hline Myb59 gDNA & TTTTAATAAG & ATGCAGTAAG & TTGTCTTTGA & TGTCATCTTC \\
\hline Myb59 cDNA & & & & \\
\hline $\mathrm{Ca} \mathrm{A}$ & - & - & - & - \\
\hline $\mathrm{Ph}$ An2 & - & nenen. & - nenes. & nenen. \\
\hline & & & & \\
\hline & 1110 & 1120 & & 1140 \\
\hline Myb59 gDNA & AAAAACTACT & GGAACTCACA & CCTACAAAAG & AAGCTAATAA \\
\hline Myb59 cDNA & AAAAACTACT & GGAACTCACA & CCTACAAAAG & AAGCTAATAA \\
\hline $\mathrm{CaA}$ & AAAAACTACT & GGAACTCACA & CCTACAAAAG & AAGCTAATAA \\
\hline $\mathrm{Ph}$ An2 & AAAAACTATT & GGAACACCCA & СCTTCGAAAG & AAGTTAATTG \\
\hline & & & R3 & \\
\hline & 1210 & 1220 & 1230 & 1240 \\
\hline Myb59 gDNA & TACTAAGACC & TCGCCCTCGG & АССТTCTCAT & CAAGTGCAAA \\
\hline Myb59 cDNA & TACTAAGACC & TCGCCCTCGG & ACCTTCTCAT & CAAGTGCAAA \\
\hline Ca A & TACTAAGACC & TCGCCCTCGG & ACCTTCTCAT & CAAGTGCAAA \\
\hline $\mathrm{Ph}$ An2 & TAATAAAACC & TCGTCCTCGG & ACCTTCTCAA & GGCCGGCAAT \\
\hline & 1310 & 1320 & 1330 & 1340 \\
\hline Myb59 gDNA & CGAACGCGAC & AAAGAAATAG & GACTAAATAT & TTGTCAGAAG \\
\hline Myb59 cDNA & CGAACGCGAC & AAAGAAATAG & GACTAAATAT & TTGTCAGAAG \\
\hline Ca $\mathrm{A}$ & CGAACGCGAC & AAAGAAATAG & GACTAAATAT & TTGTCAGAAG \\
\hline $\mathrm{Ph}$ An2 & TGAAGGTGAC & ACAGAAATAA & TAAAGTTTAG & TGATGAGAAG \\
\hline & 14 & 1420 & 1430 & 1440 \\
\hline Myb59 gDNA & GAAAATTGCA & GAAGTTGA & AGATGT- & GGCTGCAGTT \\
\hline Myb59 cDNA & AAATTGCA & AGGAAATTGA & GGAAGATGT - & GGCTGCAGTT \\
\hline Ca A & GAAAATTGCA & AGGAAATTGA & GGAAGATGT- & GGCTGCAGTT \\
\hline Ph An2 & GCCAACAACA & TTGAGATTGA & GGAATTAGTT & AGTTGTAATT \\
\hline & & & & 154 \\
\hline Myb59 gDNA & & & AT & BATGAC \\
\hline Myb59 cDNA & & & & TTGAC \\
\hline & & & & \\
\hline $\mathrm{Ph}$ An2 & CTTACT -- & ... CAAGGAG & GAGGAAGTGG & CTTAAGTGAC \\
\hline & & & & \\
\hline & & A & ATTGA & AGCAGTA \\
\hline CDNA & & & GTATTGA & -AGCAGT \\
\hline & & AT & GTATTGAA & G--AGCAGTA \\
\hline $\mathrm{Ph}$ An2 & TTAAGATTAT & GAACTTGTAA & TAGAAATATA & ATTAATAGCT \\
\hline & & & & \\
\hline & IATCAC & TTTTCATA & AAGAGT & TAAATTATTC \\
\hline Myb5 & GGTC & TATTTTCA & TTAAGAGT & TAAATTATTC \\
\hline & TCA & TATTTTCATA & TTAAGAGTTT & TAAATTATTC \\
\hline $\mathrm{Ph}$ An2 & GAATTATAAT & TATTATT-TA & TTAAAAAAT- & -AAAATATTT \\
\hline & 1810 & 1820 & 1830 & 1840 \\
\hline $\begin{array}{l}\text { Myb59 } \\
\text { Myb59 } \\
\text { cDNA }\end{array}$ & & & & \\
\hline $\mathrm{Ca} A$ & AGGGTTATAA & AGGGTTATAA & ATTATATGTT & TTCACGTGTT \\
\hline
\end{tabular}

Fig. 2. Nucleotide sequence alignment of the full-length $M y b_{A}$ genomic and cDNA clones from anthocyanin-pigmented Capsicum annuum genotype 06C59 (Myb59). Comparative $M y b$ cDNA sequence data from GenBank for C. annuum [Ca A (GenBank accession AJ608992)] and Petunia $\times$ hybrida [Ph An2 (GenBank accession AF146702)] cDNA are shown. The R2R3 Myb domain is underlined. Start and stop codons are highlighted in bold. Dissimilarities in nucleotide sequence between R2R3 regions in respective $M y b$ clones are highlighted in gray. 
of all three of these biosynthetic pathway genes was evident between our genotypes with contrasting anthocyanin pigmentation. Therefore, it appears that different genotypes have different anthocyanin gene expression patterns. This is not unexpected because tissue-specific anthocyanin pigmentation in C. annuum has independently evolved (Stommel and Bosland, 2006).

Genotype 5226 was derived from round-fruited $C$. annuum germplasm, while genotype 06C59 was derived from elongated Tabasco type $C$. annuum germplasm. The unpigmented genotype PI 159234 was derived from $C$. chinense, and the unpigmented genotype 06C19-2 was derived from C. annuum germplasm. Unlike previous studies, we used genetically related lines to contrast anthocyanin and anthocyanin-free gene expression.

Our $M y b_{A}$ cDNA sequence was identical to the sequence reported by Borovsky et al. (2004). Analysis of the genomic sequence revealed two introns of 249 and $441 \mathrm{bp}$, both of which were between the R2R3 domains (Fig. 2). As expected, the R2R3 domains were conserved between the two Solanaceous genera, Petunia and Capsicum. The sequence of the non-R2R3 domains was not conserved, with very little homology in these related genera. Comparisons are restricted to coding regions because a full-length $P$. $\times$ hybrida genomic $M y b$ is not available. In unrelated species, Malus $\times$ domestica Borkh. (apple) and Ipomoea batatas (L.) Lam. var. batatas (sweetpotato), the Myb controlling anthocyanin production had two introns between the R2 and R3 domains. In M. xdomestica, the first intron between R2 domains was $323 \mathrm{bp}$, while the second intron between R3 domains was 3000 bp (Takos et al., 2006). In $I$. batatas, the first intron between the R2 domains was $131 \mathrm{bp}$, while the second intron between R3 domains was 720 bp (Mano et al., 2007). Interestingly, the $M y b$ controlling trichome development in Gossypium hirsutum L. (cotton) also contains two introns between the R2 and R3 domains (Wang et al., 2004). The first intron acts as an enhancer in trichome development and a repressor in the development of other cell types. This is similar to what was found for the $c M y b$ in mouse (Mus musculus L.) (Seib et al., 1994). In the mouse $c M Y B$, there are 10 introns; however, only intron 4 was critical for expression.

It is widely accepted that the anthocyanin biosynthesis pathway is regulated largely by the MYB-MYC-WD regulatory protein complex (Koes et al., 2005). These transcription factors form a complex that binds to structural gene promoters, thereby modulating gene expression. WDs serve as a platform for protein-protein interactions with MYCs, which in turn recruit MYBs to form a transcription complex. The working hypothesis is that the ubiquitous WD interacts with multiple MYCs, and each MYC enlists different MYBs that eventually bind to the unique target gene to initiate gene expression.

We demonstrate that differential expression of $M y b_{A}$ as well as $M y c$ is required for anthocyanin accumulation in $C$. annuum. Prior pepper investigations were confined to the study of $M y b_{A}$ regulatory gene expression (Borovsky et al., 2004). Consistent with our results, $M y b_{A}$ expression in the anthocyaninpigmented genotype 5226 was differentially expressed in anthocyanin-pigmented and unpigmented tissues.

There was no difference in the expression of $W d$ in pigmented versus unpigmented tissue. This lack of differential $W D$ expression in pigmented and unpigmented tissue was also observed in Phalaenopsis Blume by Ma et al. (2009). This observation was explained by the network regulation model as discussed above because MYB and MYC together appeared to be sufficient to dictate the specificity of the regulatory complex.

Structural gene regulation is defined by the diversity among the anthocyanin $M y c$ and $M y b$ alleles, each of which regulates expression in a different manner. For example, in $P$. $\times$ hybrida, the combination $M y c_{A n 1} / M y b_{A n 2}$ induces anthocyanin pigmentation in the flower, whereas the $M y c_{A n 1} / M y b_{P h 4}$ combination induces vacuolar acidification (Quattrocchio et al., 2006). In addition to controlling structural gene expression, these regulatory genes can also control their own expression. In $A$. thaliana seed, a MYC, MYB, WD40 complex controls flavonoid structural gene transcription. This same complex also controls the transcription of one its members (Myc) (Baudry et al., 2006).

The relative proportions of MYB and MYC can also influence transcription factor activation of anthocyanin structural genes. Using transient expression assays, Ma et al. (2008) demonstrated that altered ratios of $M y b: M y c$ transcript produced varying levels of anthocyanin accumulation in normally white Phalaenopsis flowers. High levels of $M y b$ expression in conjunction with low or high levels of $M y c$ expression were required to elicit high levels of anthocyanin accumulation. Neither regulatory gene alone was sufficient to elicit anthocyanin production. We also observed varying $M y b: M y c$ transcript ratios in $C$. annuum. $M y b_{A}: M y c$ transcript ratios were $\approx 4$-fold greater in fruit and flower $\left(M y b_{A}: M y c\right.$ transcript ratio 2.89 and 4.12 , respectively) tissue of the anthocyanin-free 06C19-2 in comparison with corresponding anthocyanin-pigmented fruit and flower $\left(M y b_{A}: M y c\right.$ transcript ratio 0.63 and1.00, respectively) tissues in 06C59. Results from Z. mays (deMajnik et al., 1998) suggested that the threshold requirement for the regulatory genes to activate anthocyanin production is different in different plants. The low $M y b_{A}$ and $M y c$ expression levels observed in our nonanthocyanin-pigmented $C$. annuum flower and fruit tissues suggest that differential expression of these regulatory genes is likely the primary determinant of anthocyanin pigmentation in these genotypes.

In contrast to $C$. annuum flowers and fruit, differential expression of $M y b_{A}$ and $M y c$ was not observed in foliar tissue, suggesting that a different mechanism contributes to the regulation of anthocyanin biosynthesis in foliage. Likewise, differences in $M y b_{A}$ and $M y c$ expression were not responsible for the difference observed in anthocyanin structural gene expression under inductive and noninductive environmental conditions for foliar anthocyanin accumulation (Lightbourn et al., 2007). Inheritance studies also demonstrated that the genetic control of anthocyanin accumulation in $C$. annuum flowers and fruit is different from that in foliage. Whereas anthocyanin-based flower and fruit color can be separated into discreet classes, a continuous range of color scores is evident in breeding populations segregating for foliar pigmentation (Stommel and Griesbach, 2008). High broad sense and narrow sense heritability for foliar anthocyanin pigmentation indicate that inheritance of foliar anthocyanin is more complex and is not limited to the action of $A$ and $M o A$. Additive gene action and epistasis contribute to foliar anthocyanin pigmentation.

A possible mechanism that may explain our results involves miRNA. miRNAs control gene expression by targeting specific mRNAs for degradation (Bartel, 2004; Jones-Rhoades et al., 2006; Kidner and Marteinssen, 2005). miRNAs 21 to 22 nucleotides in length are involved in post-transcriptional gene 
silencing by targeting mRNAs for degradation via an endonuclease complex (Baulcombe, 2004; Jones-Rhoades et al., 2006).

Preliminary observations suggest that miRNAs could be involved in regulating anthocyanin gene expression in C. annuum leaves. One of the symptoms we observed following tobacco etch virus infection of purple-leaved $C$. annuum plants was a reduction in anthocyanin pigmentation (data not shown). C. annuum fruit from virus-infected plants can display differential anthocyanin pigmentation (Black et al., 1991). Viral infection is known to modify host gene expression by suppressing RNA silencing. Glycine max L. seeds are normally yellow due to the presence of Chs miRNAs (Senda et al., 2004). When infected with soybean mosaic potyvirus, there was an increase in Chs mRNA that restored anthocyanin seed color. In the $P$. $\times$ hybrida Star mutant, virus infection can restore anthocyanin production in white Star floral tissue by inhibiting miRNA or siRNA formation responsible for absence of chalcone synthase (Koseki et al., 2005). Further studies are planned to examine anthocyanin biosynthetic and regulatory miRNA genes in C. annuum.

\section{Literature Cited}

Bartel, D.P. 2004. MicroRNAs: Genomics, biogenesis, mechanism and function. Cell 16:281-297.

Baudry, A., M. Caboche, and L. Lepiniec. 2006. TT8 controls its own expression in a feedback regulation involving TTG1 and a homologous MYB and bHLH factors, allowing a strong and cell specific accumulation of flavonoids in Arabidopsis thaliana. Plant J. 46:768779 .

Baulcombe, D. 2004. RNA silencing in plants. Nature 431:356-363.

Black, L.L., S.K. Green, G.L. Hartman, and J.M. Poulus. 1991. Pepper diseases, a field guide. Asian Veg. Res. Dev. Center, Taipei, Taiwan. Borovsky, Y., M. Oren-Shamir, R. Ovadia, W. deJong, and I. Paran. 2004. The $A$ locus that controls anthocyanin accumulation in pepper encodes a $M Y B$ transcription factor homologous to Anthocyanin2 of Petunia. Theor. Appl. Genet. 109:23-29.

Carey, C.C., J.T. Strahle, D.A. Selinger, and V.L. Chandler. 2004. Mutations in the pale aleurone colorl regulatory gene of the Zea mays anthocyanin pathway have distinct phenotypes relative to the functionally similar TRANSPARENT TESTA GLABRA1 gene in Arabidopsis thaliana. Plant Cell 16:450-464.

Coe, E.H., S. McCormick, and S.A. Modena. 1981. White pollen in maize. J. Hered. 72:318-320.

Cone, K.C., F.A. Burr, and B. Burr. 1986. Molecular analysis of the maize anthocyanin regulatory locus $C 1$. Proc. Natl. Acad. Sci. USA 83:9631-9635.

Cone, K.C., S.M. Cocciolone, C.A. Moehlenkamp, T. Wever, B.J. Drummond, L.A. Tagliani, B.A. Bowen, and G.H. Perrot. 1993. Role of the regulatory gene $p l$ in the photocontrol of maize anthocyanin pigmentation. Plant Cell 5:1807-1816.

deMajnik, J., G. Tanner, R. Joseph, P. Larkin, J. Weinman, M. Djordjevic, and B. Rolfe. 1998. Transient expression of maize anthocyanin regulatory genes influences anthocyanin production in white clover and peas. Aust. J. Plant Physiol. 25:335-343.

Deshpande, R.B. 1933. Studies in Indian chilies. 3. The inheritance of some characters in Capsicum annuum L. Indian J. Agr. Sci. 3:219300 .

deVetten, N., F. Quattrocchio, J. Mol, and R. Koes. 1997. The an11 locus controlling flower pigmentation in Petunia encodes a novel WD-repeat protein conserved in yeast, plants and animals. Genes Dev. 11:1422-1434.

Dooner, H.K. 1983. Coordinate genetic regulation of flavonoid biosynthetic enzymes in maize. Mol. Gen. Genet. 189:136-141.

Dooner, H.K., T.P. Robbins, and R.A. Jorgensen. 1991. Genetic and developmental control of anthocyanin biosynthesis. Annu. Rev. Genet. 25:173-199.
Griesbach, R.J. 2005. Biochemistry and genetics of flower color. Plant Breed. Rev. 25:89-114.

Griesbach, R.J. and R.M. Beck. 2005. Sequence analysis of the chalcone synthase gene in four Petunia taxa. J. Amer. Soc. Hort. Sci. 130:360-365.

Griesbach, R.J., S. Asen, and B.A. Leonhardt. 1991. Petunia hybrida anthocyanins acylated with caffeic acid. Phytochemistry 30:1729-1731.

Grotewold, E. and T. Peterson. 1994. Isolation and characterization of a maize gene encoding chalcone flavonone isomerase. Mol. Gen. Genet. 242:1-8.

Holton, T.A. and E.C. Cornish. 1995. Genetics and biochemistry of anthocyanin biosynthesis. Plant Cell 7:1071-1083.

Huits, H.S.M., A.G.M. Gerats, M.M. Krelke, J.N.M. Mol, and R. Koes. 1994. Genetic control of dihydroflavonol 4-reductase gene expression in Petunia hybrida. Plant J. 6:295-310.

Jones-Rhoades, M.W., D.P. Bartel, and B. Bartel. 2006. MicroRNAs and their regulatory roles in plants. Annu. Rev. Plant Biol. 57:19-53.

Kidner, C.A. and R.A. Marteinssen. 2005. The developmental role of microRNA in plants. Curr. Opin. Plant Biol. 8:39-44.

Koes, R., W. Verweij, and F. Quattrocchio. 2005. Flavonoids: A colorful model for the regulation and evolution of biochemical pathways. Trends Plant Sci. 10:236-242.

Koes, R.E., C.E. Spelt, and J.N. Mol. 1989. The chalcone synthase multigene family of Petunia hybrida (V30): Differential, lightregulated expression during flower development and UV light induction. Plant Mol. Biol. 12:213-225.

Koseki, M., K. Goto, C. Masuta, and A. Kanazawa. 2005. The Startype color pattern in Petunia hybrida 'Red Star' flowers is induced by sequence-specific degradation of chalcone synthase RNA. Plant Cell Physiol. 46:1879-1883.

Lightbourn, G.J., J.R. Stommel, and R.J. Griesbach. 2007. Epistatic interactions influencing anthocyanin gene expression in Capsicum annuum. J. Amer. Soc. Hort. Sci. 132:824-829.

Lightbourn, G.J., R.J. Griesbach, J.A. Novotny, B.A. Clevidence, D.D. Rao, and J.R. Stommel. 2008. Effects of anthocyanin and carotenoid combinations on foliage and immature fruit color of Capsicum annuum L. J. Hered. 99:105-111.

Ma, H., M. Pooler, and R. Griesbach. 2008. Ratio of $M y c$ and $M y b$ transcription factors regulates anthocyanin production in orchid flowers. J. Amer. Soc. Hort. Sci. 133:133-138.

Ma, H., M. Pooler, and R. Griesbach. 2009. Anthocyanin regulatory/ structural gene expression in Phalaenopsis Blume. J. Amer. Soc. Hort. Sci. (In press).

Mano, H., F. Ogasawara, K. Sato, H. Higo, and Y. Minobe. 2007. Isolation of a regulatory gene of anthocyanin biosynthesis in tuberous roots of purple-fleshed sweet potato. Plant Physiol. 143:1252-1268.

Martin, C. and J. Paz-Ares. 1997. MYB transcription factors in plants. Trends Genet. 13:67-73.

Peterson, P.A. 1959. Linkage of fruit shape and color genes in Capsicum. Genetics 44:407-419.

Pfaffl, M.W. 2001. A new mathematical model for relative quantification in real-time RT-PCR. Nucleic Acids Res. 29:2002-2007.

Quattrocchio, F., W. Verweij, A. Kroon, C. Spelt, J. Mol, and R. Koes. 2006. PH4 of Petunia is an R2R3MYB protein that activates vacuolar acidification through interactions with basic-helix-loop-helix transcription factors of the anthocyanin pathway. Plant Cell 18:1274-1291.

Ramsay, N.A. and B.J. Glover. 2005. MYB-bHLH-WD40 protein complex and the evolution of cellular diversity. Trends Plant Sci. 10:63-70.

Seib, T., C. Welter, M. Engel, B. Theisinger, and S. Dooley. 1994. Presence of regulatory sequences within intron 4 of human and murine c-myb genes. Biochim. Biophys. Acta 1219:285-292.

Senda, M., C. Masuta, S. Ohnishi, K. Goto, A. Kasai, T. Sano, J.-S. Hong, and S. MacFarlane. 2004. Patterning of virus-infected Glycine max seed coat is associated with suppression of endogenous silencing of chalcone synthase genes. Plant Cell 16:807-818. 
Smith, T.F. 1999. The WD repeat: A common architecture for diverse functions. Trends Biochem. Sci. 24:181-185.

Stommel, J.R. and P.W. Bosland. 2006. Ornamental pepper, Capsicum annuum, p. 561-599. In: N.O. Anderson (ed.). Flower breeding and genetics: Issues, challenges and opportunities for the 21 st Century. Springer, Dordrecht, The Netherlands.

Stommel, J.R. and R.J. Griesbach. 2008. Inheritance of fruit, foliar and plant habit attributes in Capsicum L. J. Amer. Soc. Hort. Sci. 133:396-407.

Takos, A.M., F.W. Jaffé, S.R. Jacob, J. Bogs, S.P. Robinson, and A.R. Walker. 2006. Light-induced expression of a $M Y B$ gene regulates anthocyanin biosynthesis in red apples. Plant Physiol. 142:1216-1232.

van Tunen, A.J., R.E. Koes, C.E. Spelt, A.R. van der Krol, A.R. Stuitje, and J.N.M. Mol. 1988. Cloning of the two chalcone flavanone isomerase genes from Petunia hybrida: Coordinate light-regulated and differential expression of flavonoid genes. EMBO J. 7:1257-1263. van Tunen, A.J., S.A. Hartman, L.A. Mur, and J.N.M. Mol. 1989. Regulation of chalcone flavone isomerase (CHI) gene expression in Petunia hybrida: The use of alternative promoters in corolla, anthers and pollen. Plant Mol. Biol. 12:539-551.

Wang, S., J. Wang, N. Yu, C. Li, B. Luo, J. Gou, L. Wang, and X. Chen. 2004. Control of plant trichome development by a cotton fiber MYB gene. Plant Cell 16:2323-2334.

Winkel-Shirley, B. 2001. Flavonoid biosynthesis. A colorful model for genetics, biochemistry, cell biology, and biotechnology. Plant Physiol. 126:485-493.

Yamazaki, M., E. Yamagishi, Z. Gong, M. Fukuchi-Mizutani, Y. Fukui, Y. Tanaka, T. Kusumi, M. Yamaguchi, and K. Saito. 2002. Two flavonoid glucosyltransferases from Petunia hybrida: Molecular cloning, biochemical properties and developmental regulated expression. Plant Mol. Biol. 8:401-411. 